Research Article

\title{
Analysis of the Fluctuation of Bank Interest Rate Based on Computer Statistical Model and Machine Learning
}

\author{
Jiangning Cao $\mathbb{D}^{1,2}$ \\ ${ }^{1}$ School of Business Administration, Zhongnan University of Economics and Law (ZUEL), Wuhan 430000, China \\ ${ }^{2}$ Business College, Xinyang Normal University (XYNU), Xinyang 464000, China \\ Correspondence should be addressed to Jiangning Cao; doudou@xynu.edu.cn
}

Received 10 September 2021; Revised 23 October 2021; Accepted 5 November 2021; Published 18 November 2021

Academic Editor: Mu Zhou

Copyright (c) 2021 Jiangning Cao. This is an open access article distributed under the Creative Commons Attribution License, which permits unrestricted use, distribution, and reproduction in any medium, provided the original work is properly cited.

\begin{abstract}
In order to improve the effect of bank interest rate volatility analysis, this article combines actual conditions and machine learning algorithms to construct a fluctuation analysis model of bank interest rate based on computer statistical model and machine learning. For the data with system transformation, the data contains stationary and nonstationary processes; so, the power of the standard unit root test is low. This paper therefore proposes a new unit root test method. From demand analysis, system design to system implementation, and testing, advanced software engineering-related ideas are adopted, and the bank's interest rate management system is designed and implemented in strict accordance with software development-related processes. This paper adopts the modular design idea, classifies the functions to be realized according to their content, and conducts structural verification and performance analysis of the functional modules. Through experimental analysis, we can see that the system model constructed in this paper has certain effects in the analysis of interest rate fluctuations.
\end{abstract}

\section{Introduction}

With the continuous improvement of China's financial market mechanism and the continuous enrichment of market levels, the interest rate sensitivity of microentities has been greatly improved. Moreover, the development of China's economy has gradually shifted from extensive development to sustainable development based on structural optimization, and the shortcomings of quantitative monetary policies have gradually become apparent. In order to cope with this change in the development mode, the monetary and credit policy is changing from "overflow irrigation" to "precision drip irrigation." Therefore, it is very important to establish a price-guided financial market operation mechanism and a monetary policy guidance mechanism [1].

To implement a financial market operation mechanism based on price guidance, first of all, it is necessary to cultivate the sensitivity of microentities to prices. In addition to a complete market mechanism, it also requires the stable and orderly operation of the financial market. The central bank's monetary policy is predictable, and the central bank's monetary policy toolbox contains a wealth of tools to deal with different financial shocks [2]. Therefore, on the one hand, the financial market needs to build a stable marketbased benchmark interest rate. The benchmark interest rate is determined by a market-based mechanism and can accurately reflect the liquidity fundamentals of the financial market. In addition, it is necessary to ensure the smooth operation of the benchmark interest rate of the money market and the ability to dilute liquidity shocks and ensure the smooth transmission of monetary policy guidance from the short-term money market to the long-end capital market and then to the real economy. On the other hand, the central bank has a strong ability to guide the benchmark interest rate. Based on this, the reform of interest rate marketization is imperative. Therefore, studying the characteristics of currency market interest rate fluctuations and how effective influencing factors affect money market interest rate volatility is of great significance for the central bank to gradually improve its ability to guide money market interest rates and improve the predictability of money market liquidity shocks, thereby improving participants' resilience. Judging 
from the development of benchmark interest rates in my country's currency market at this stage, the current benchmark interest rates in the financial market consist of interbank lending rates, banker pledged repo rates, and money market interest rate systems such as SHIBOR that our country is vigorously fostering [3]. Judging from its volatility characteristics, the interest rate volatility of the Chinese currency market is much higher than that of other countries. As the People's Bank of China implements a liquidity management framework with structural liquidity shortage, when liquidity is relatively short, the preventive liquidity demand of commercial banks will rise sharply, which will lead to substantial fluctuations in interbank money market interest rates. However, after the Central Bank began to focus on building an interest rate corridor mechanism that stabilizes the liquidity expectations of commercial banks, the fluctuation of interest rates in the interbank money market has dropped significantly. In recent years, on the one hand, the central bank has focused on building a currency market benchmark interest rate with global representative capabilities, ensuring that its fluctuations can represent the actual situation of currency market liquidity shocks and controlling its fluctuations within a certain range. On the other hand, the government has built a rich monetary policy tool system, stabilized the liquidity impact expectations of commercial banks, improved the predictability of monetary policy, strengthened the central bank's ability to guide the money market benchmark interest rate, and reduced the friction of monetary policy in the money market-credit market-real economic transmission channel.

Based on the above analysis, this article analyzes the fluctuation of bank interest rates based on computer statistical models and machine learning models.

\section{Related Work}

The literature [4] constructed a stochastic model specifically used for commercial banks to describe changes in their deposit reserve requirements under different circumstances and studied the related issues of commercial banks' reserve requirements in more detail and indepth. The literature [5] analyzed the specific operation process of the interest rate corridor monetary policy control framework. The research shows that even under the zero reserve policy, the central bank's monetary policy can be very effective. Because the primary goal of commercial banks is to maximize their own profits, the central bank adjusts the width of the interest rate corridor by changing the upper and lower limits of the interest rate corridor. Without the need for open market operations, the lending rate of commercial banks will be controlled near the target interest rate expected by the central bank. The literature [6] used the method of establishing a geometric model to study and elaborate the basic and operating principles of the interest rate corridor in detail. It is believed that if the settlement balance of commercial banks at the end of each trading day can be controlled at zero, then through the control of interest rate corridors, the basic interest rate of the money market can be stabilized near the central bank's target interest rate. The research in the litera- ture [7] is based on the commercial bank reserve requirement model. Moreover, it pointed out that if the central bank's policy target interest rate can be higher than the midpoint of the interest rate corridor, then the central bank's level of short-term market interest rate regulation will not be affected by the interest rate corridor range and the size of the policy target interest rate. The research of the literature [8] is from the perspective of social welfare. It is believed that the interest rate in the corridor should be set to a width greater than zero, so as to optimize the effect of monetary policy. The literature [9] believes that the policy control effect of the interest rate corridor is far superior to the traditional open market operation, but it believes that if only the interest rate corridor is used as a control method, it will reduce the efficiency of cash distribution. Therefore, the optimal method of monetary control policy should be a combination of interest rate corridors and open market operations. The literature [10] analyzed the new form of "floor-style" interest rate corridors that emerged after the financial crisis. It is believed that once the width of the interest rate corridor is set by the central bank, if the overall mobile interest rate corridor model does not change its width, the final control effect of the interest rate corridor on market interest rates will not be affected. The literature [11] believes that the core of the interest rate corridor, the monetary policy control framework, is the width of the interest rate corridor. The literature [12] pointed out in the research that the Fed's rediscount window is an emergency funding aid, not a regular loan facility; so, commercial banks will only apply for special circumstances. In addition, interest on deposit reserves is not available to all commercial banks. Sometimes, market segmentation occurs in the federal funds market, which will cause market interest rates to fall below the lower limit of the interest rate corridor and cause market interest rates to deviate for a long time. The literature [13] elaborated on the specific practice of adopting zero reserve system and interest rate corridor in some countries in the world. The literature [14] summarized the actual experience of China's open market operations, in which the upper limit interest rate of the interest rate corridor is selected as the overnight automatic pledge financing interest rate, and the lower limit interest rate of the interest rate corridor is selected as the reserve interest rate. The literature [15] elaborated on the origin, development, and mechanism of the interest rate corridor and explored the optimal width of the interest rate corridor and the influence of the benchmark interest rate of the money market on the interest rate corridor. The literature [16] compared the monetary policy framework of interest rate corridor with traditional open market operations and believed that our national central bank should adopt both interest rate corridor and open market operations to achieve the best regulatory effect. The literature [17] selected several typical countries and regions that have implemented interest rate corridors to prove that in the same period, the short-term market interest rate fluctuations of countries that have implemented interest rate corridors are lower than those of countries that have not implemented interest rate corridors. Moreover, the narrower the interest rate corridor, the less volatility of short-term 
market interest rates. The literature [18] analyzed the regulation mechanism and regulation characteristics of the interest rate corridor, a monetary policy framework. The literature [19] believes that China's implementation of the interest rate corridor monetary policy framework is a positive response to the reform of interest rate marketization, which reduces social financing costs, improves market efficiency, and has played a strong role in promoting the pricing basis of China's marketized interest rates. The literature [20] elaborated and analyzed the operation of the interest rate corridor and analyzed the advantages and disadvantages, which can help the construction of the interest rate corridor.

\section{Interest Rate Fluctuation Analysis Algorithm}

We set $s_{t}$ as a random variable, which can be assumed to take only an integer value $\{1,2, \cdots, N\}$.

$$
P\left\{s_{t}=j \mid s_{t-1}=i, s_{t-2}=k, \cdots\right\}=P\left\{s_{t}=j \mid s_{t-1}=i\right\}=P_{i j} .
$$

Such a process is called an $N$-state Markov chain with transition probability $\left\{P_{i j}\right\}_{i, j=1, \cdots, N}$.

$$
P_{i 1}+P_{i 2}+\cdots+P_{\mathrm{iN}}=1
$$

It is often convenient to list the transition probabilities as an $(N \times N)$ matrix $P[21]$.

$$
P=\left[\begin{array}{cccc}
P_{11} & P_{21} & \cdots & P_{N 1} \\
P_{12} & P_{22} & \cdots & P_{N 2} \\
\cdots & \cdots & \cdots & \cdots \\
P_{1 N} & P_{2 N} & \cdots & P_{N N}
\end{array}\right]
$$

The element in the $j$-th row and the $i$-th column of $P$ is the transition probability $P_{i j}$.

Generally, when an $N$-state Markov chain is reducible, if there is a way to indicate each state, the transition matrix can be written as follows:

$$
P=\left[\begin{array}{ll}
B & C \\
0 & D
\end{array}\right] \text {. }
$$

Among them, $B$ represents $(K \times K)$ matrix, $1 \leq K<N$. If a Markov chain is not reducible, it is called irreducible.

An $N$-state irreducible Markov chain with a transition matrix of $P$ is investigated. If one eigenvalue of $P$ is assumed to be 1 and the remaining eigenvalues of $P$ all fall within the unit circle, the Markov chain is called traversal. The $(N \times 1)$ vector of the traversal probability of a traversal chain is denoted as $\pi$. This vector $\pi$ is defined as the feature vector $h$ corresponding to the unit feature root of $P$; that is, the traversal probability vector $\pi$ satisfies [22]:

$$
P \pi=\pi
$$

The feature vector $\pi$ is a normalized vector; so, the sum of its elements is 1 . It can be proved that if $P$ is the transition matrix traversing the Markov chain, then

$$
\lim _{m \rightarrow \infty} P^{m}=\pi * 1^{\prime}
$$

The traversal probability vector $\pi$ can be interpreted as an unconditional probability vector.

The following describes how to calculate the traversal probability of an $N$-state Markov chain.

For a general process of traversing $N$ states, the unconditional probability vector represents a vector $\pi$, and $\pi$ has properties $P \pi=\pi$ and $1^{\prime} \pi=1$, where 1 represents an $(N \times 1)$ vector that each element is 1 .

We therefore look for a $\pi$ that satisfies the following formula [23]:

$$
A \pi=e_{N+1} .
$$

Among them, $e_{N+1}$ represents the $(N+1)$-th column of $I_{N+1}$, and

$$
\underset{(N+1) \times N}{A}=\left[\begin{array}{c}
I_{N}-P \\
1^{\prime}
\end{array}\right] .
$$

Such a solution can be obtained by multiplying the front of formula (7) by $\left(A^{\prime} A\right)^{-1} A^{\prime}$ :

$$
\pi=\left(A^{\prime} A\right)^{-1} A^{\prime} e_{N+1} .
$$

That is, $\pi$ is the $(N+1)$-th column of matrix $\left(A^{\prime} A\right)^{-1} A^{\prime}$.

3.1. Parameter Estimation of Markov System Transformation Model. The Markov system transformation model is mainly used to model data containing system changes. The general model studied in this paper is as follows. We set $y_{t}$ as an observed endogenous variable $(n \times 1)$ vector and $x_{t}$ as an observed exogenous variable $(k \times 1)$ vector. If the process is controlled by the system $s_{t}=j$ in period $t$, the conditional density of $y_{t}$ is assumed to be

$$
f\left\{y_{t} \mid s_{t}=j, x_{t}, Y_{t-1} ; \alpha\right\}
$$

Among them, $\alpha$ is a parameter vector that characterizes the conditional density. If there are $N$ different systems, then there are $N$ different densities represented by the above formula, $j=1,2, \cdots, N$. These densities will be listed as an $(N \times 1)$ vector, denoted as $\eta_{t}$.

For a first-order autoregressive, its constant term and autoregressive coefficient can be different on different subsamples:

$$
y_{t}=c_{s_{t}}+\Phi_{s_{t}} y_{t-1}+\varepsilon_{t}
$$

Among them, $\varepsilon_{t} \sim$ i.i.d. $N\left(0, \sigma^{2}\right)$. System $s_{t}$ is regarded as the unobserved consequence of the $N$-state Markov chain to model. $s_{t}$ is independent of $\varepsilon_{t}$ for all $t$ and $\tau$. 
Thus, for the example described in the above formula, $y_{t}$ is a quantity $(n=1)$, and the exogenous variable only contains a constant term $\left(x_{t}=1\right)$. The unknown parameters in $\alpha$ include $c_{1}, \cdots, c_{N}, \Phi_{1}, \cdots, \Phi_{N}$ and $\sigma^{2}$. In system $N=2$, the two densities represented by the above formula are

$\eta_{t}=\left[\begin{array}{l}f\left\{y_{t} \mid s_{t}=1, y_{t-1} ; \alpha\right\} \\ f\left\{y_{t} \mid s_{t}=2, y_{t-1} ; \alpha\right\}\end{array}\right]=\left[\begin{array}{l}\frac{1}{\sqrt{2 \pi} \sigma} \exp \left\{\frac{-\left(y_{t}-c_{1}-\Phi_{1} y_{t-1}\right)^{2}}{2 \sigma^{2}}\right\} \\ \frac{1}{\sqrt{2 \pi} \sigma} \exp \left\{\frac{-\left(y_{t}-c_{2}-\Phi_{2} y_{t-1}\right)^{2}}{2 \sigma^{2}}\right\}\end{array}\right]$.

We assume that the conditional density depends only on the current system $s_{t}$ and not on the past system:

$f\left\{y_{t} \mid x_{t}, Y_{t-1}, s_{t}=j ; \alpha\right\}=f\left\{y_{t} \mid x_{t}, Y_{t-1}, s_{t}=j, s_{t-1}=i, s_{t-1}=\kappa, \cdots, \alpha\right\}$.

We assume that $s_{t}$ evolves according to a Markov chain, and it is independent of the past observations of $y_{t}$ or the current and past observations of $x_{t}$ :

$$
P\left\{s_{t}=j \mid s_{t-1}=i, s_{t-1}=\kappa, \cdots, x_{t}, Y_{t-1}\right\}=P\left\{s_{t}=j \mid s_{t-1}=i\right\}=p_{i j} .
$$

These parameters are listed as a vector $\theta$. An important goal is to estimate the value of $\theta$ based on the observed value of $Y_{T}$. We assume that the value of $\theta$ is certain to the analyst. However, even if we know the value of $\theta$, we do not know in which system the process is located in each period in the sample. What we can do is to form a probabilistic inference as a generalization of the following formula.

$$
P\left\{s_{t}=j \mid y_{t} ; \theta\right\}=\frac{P\left\{y_{t}, s_{t}=j ; \theta\right\}}{f\left(y_{t} ; \theta\right)}=\frac{\pi_{j} \cdot f\left\{y_{t} \mid s_{t}=j ; \theta\right\}}{f\left(y_{t} ; \theta\right)} .
$$

Among them,

$$
\pi_{j}=P\left(s_{t}=j ; \theta\right), j=1, \cdots, N
$$

The above formula is the unconditional probability of the value $j$ of $s_{t}$.

This inference takes the form of conditional probability, and the analyst can arrange this probability so that the $t$-th observation value is listed as a $(N \times 1)$ vector $\widehat{\xi}_{t \mid t}$ by system $j$.

These predictions are listed as a $(N \times 1)$ vector $\widehat{\xi}_{t+1 \mid t}$, and its $j$-th element represents $P\left\{s_{t+1}=j \mid y_{t} ; \theta\right\}$.

The optimal inference and prediction for each period $t$ in the sample can be obtained by iterating the following equation:

$$
\begin{aligned}
\widehat{\xi}_{t \mid t} & =\frac{\left(\widehat{\xi}_{t \mid t-1} \odot \eta_{t}\right)}{1^{\prime}\left(\widehat{\xi}_{t \mid t-1} \odot \eta_{t}\right)} . \\
\widehat{\xi}_{t+1 \mid t} & =P \cdot \widehat{\xi}_{t \mid t} .
\end{aligned}
$$

$\eta_{t}$ represents the $(N \times 1)$ vector, the $j$-th element is the conditional density, $P$ represents the transition probability matrix, 1 represents the $(N \times 1)$ vector with each element being 1 , and $\odot$ represents the element-to-element multiplication. After the initial value $\widehat{\xi}_{1 \mid 0}$ and the assumed value $\theta$ of the overall parameter $n$ are given, the above formula can be iterated at $t=1,2, \cdots, T$ to calculate the $\widehat{\xi}_{t \mid t}$ and $\widehat{\xi}_{t+1 \mid t}$ values for each period $t$ in the sample. The value of the loglikelihood function $\ell(\theta)$ for the observed data $Y_{T}$ at $\theta$ used to form the iteration can be obtained as a by-product of this algorithm, which is

$$
\ell(\theta)=\sum_{t=1}^{T} \log f\left(y_{t} \mid x_{t}, Y_{t-1} ; \theta\right)
$$

Among them,

$$
f\left(y_{t} \mid x_{t}, Y_{t-1} ; \theta\right)=1^{\prime}\left(\widehat{\xi}_{t \mid t-1} \odot \eta_{t}\right)
$$

An initial value $\widehat{\xi}_{1 \mid 0}$ is given to calculate $\widehat{\xi}_{t \mid t}$ for any $t$. There are several options for selecting initial values. One way is to make $\widehat{\xi}_{1 \mid 0}$ equal to the unconditional probability vector, which is denoted as $\pi$. Another option is to make

$$
\widehat{\xi}_{1 \mid 0}=\rho
$$

Among them, $\rho$ is a fixed $(N \times 1)$ vector of nonnegative constants whose elements are 1 , such as $\rho=N^{-1} \cdot 1$. In addition, $\rho$ can be estimated by the maximum likelihood function, and its restriction is $1^{\prime} \rho=1$ and for $j=1, \cdots, N, \rho_{j} \geq 0$.

$\widehat{\xi}_{t \mid t}$ represents the $(N \times 1)$ vector whose $j$-th element is $P\left\{s_{t}=j \mid Y_{\tau} ; \theta\right\}$. When $t>\tau$, this represents the prediction of the system in a certain period in the future.

When we take the available information in period $t$ as the condition, and use $\widehat{\xi}_{t+m}$ to represent the forward $\mathrm{m}$ period forecast based on period $t$, we can get

$$
\left.\widehat{\xi}_{t+m}\right|_{t}=p^{m} \cdot \widehat{\xi}_{t \mid t}
$$

Smooth inference can be calculated using the algorithm established by [24]. In vector form, this algorithm can be written as

$$
\widehat{\xi}_{t \mid T} \widehat{\xi}_{t \mid t} \odot\left\{p^{t} \cdot\left[\widehat{\xi}_{t+1 \mid T}(\div) \widehat{\xi}_{t+1 \mid t}\right]\right\}
$$

Among them, the symbol $(\div)$ represents element-byelement division. The above formula is about $t=T-1, T$ 


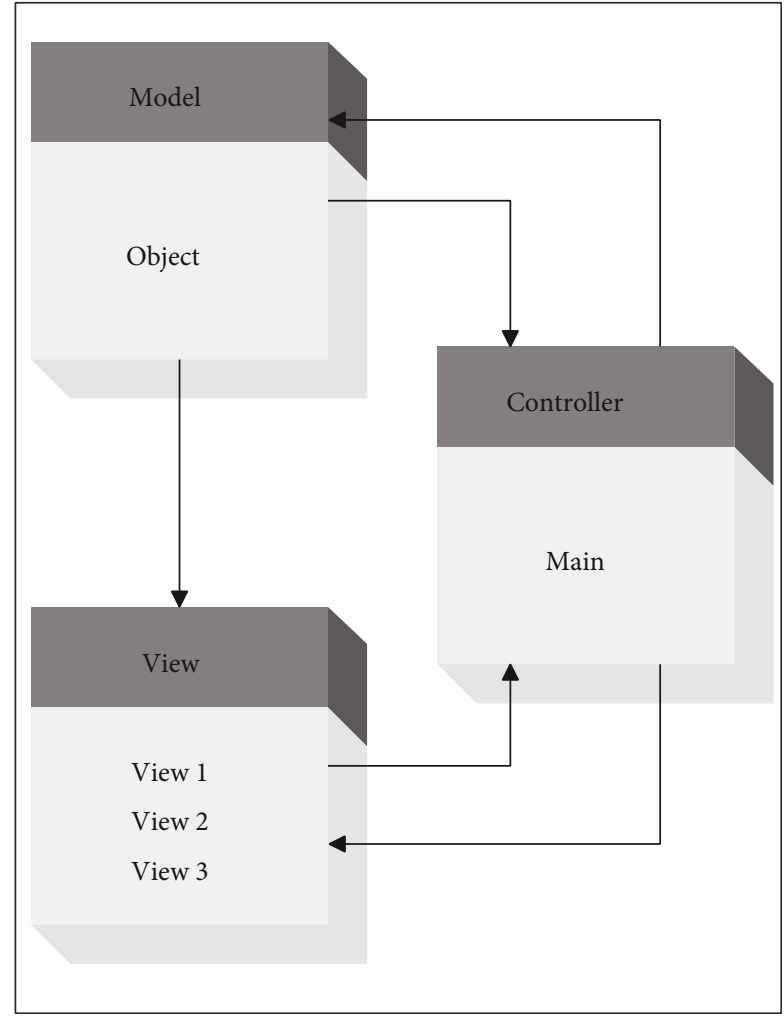

FIgURE 1: MVC model structure.

$-2, \cdots, 1$ backward iteration to get the smoothing probability $\widehat{\xi}_{t \mid T}$. The iteration starts from $\widehat{\xi}_{T \mid T}$ at $t=T$, and the algorithm is effective only when $s_{t}$ obeys a first-order Markov chain. When the conditional density depends on $s_{t}, s_{t-1}, \cdots$, only through the current state $s_{t}$, and when the lag value of the explanatory variable vector $x_{t}$ instead of $y_{t}$ is strictly exogenous, $x_{t}$ is independent of $s_{t}$ for all $t$ and $\tau$.

The parameter vector $\theta$ is taken as a fixed known vector. For a given fixed $\theta$, once the iteration is completed for $t$ $=1,2, \cdots, T$, the log likelihood value implied by the value of $\theta$ can be known according to the formula. The value of $\theta$ that maximizes the log likelihood can be obtained by the BFGS algorithm.

\section{Bank Interest Rate Analysis Model Based on Computer Statistical Model and Machine Learning}

With the support of the above interest rate algorithm, the bank's interest rate fluctuation analysis model is constructed.

In actual development, the MVC development structure is the main development structure, which mainly refers to the unified operation of the display layer, control layer, and data layer to JSP or JavaBean for processing. The following is the structure diagram of the MVC development structure, as shown in Figure 1:

To implement the MVC mode in the JavaEE development environment, the most critical part is to use the RequestDispatcher interface, because the content is saved

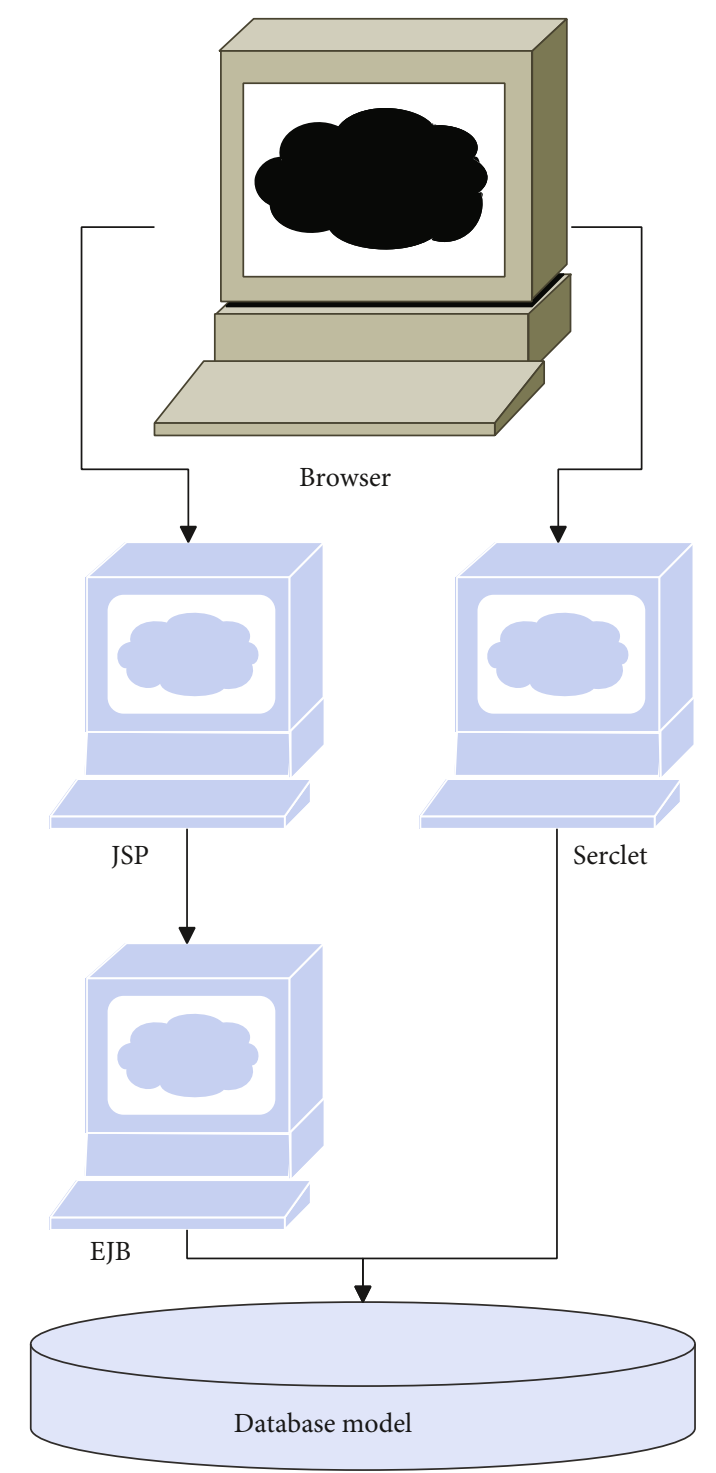

Figure 2: The architecture of the MVC pattern in J2EE.

to the JSP page for display through this interface. When a user submits a request, it will be handed over to the Servlet for processing, and then the Servlet calls the JavaBean, and the operation result of the JavaBean is passed to the JSP page through the RequestDispatcher interface. Since the content to be displayed is only valid in a request response, in the MVC design mode, all attribute transfers will be passed using the Request attribute range, which can improve the operational performance of the code, as shown in Figure 2.

The B/S structure and MVC structure adopted by this system are shown in Figure 3, and the operating structure of the application system based on the $\mathrm{B} / \mathrm{S}$ structure is shown in Figure 3. The model process is client-server database.

The MVC development structure diagram of this system is divided into three layers according to the MVC model, and the technology used each time is realized by the JavaEE development environment. The following is the architecture diagram of statistical system of bank interest rate, as shown in Figure 4. 


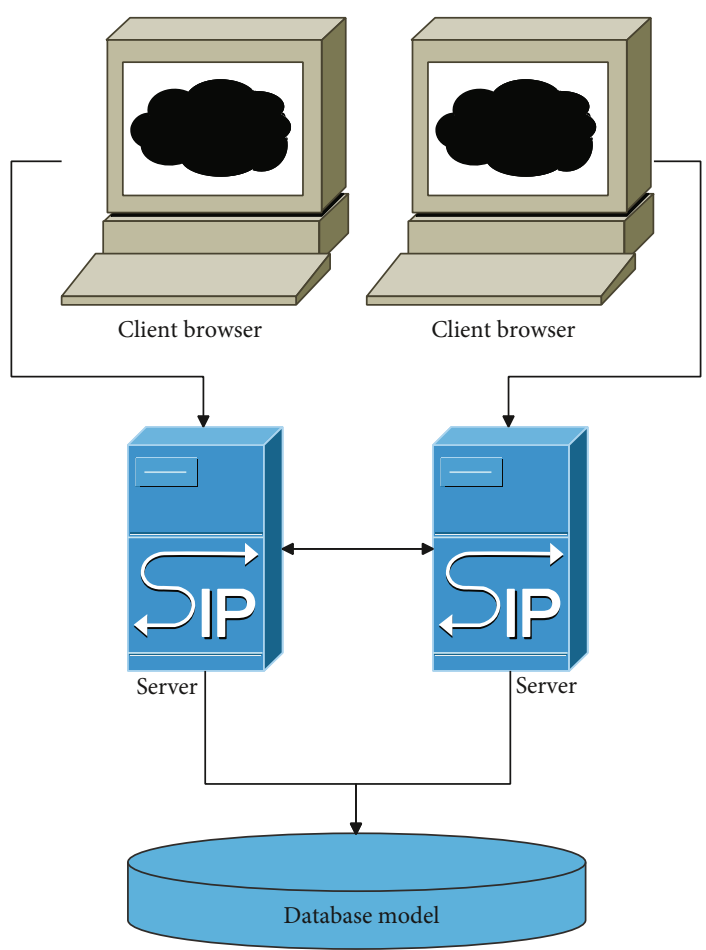

Figure 3: Three-tier structure of the system B/S model.
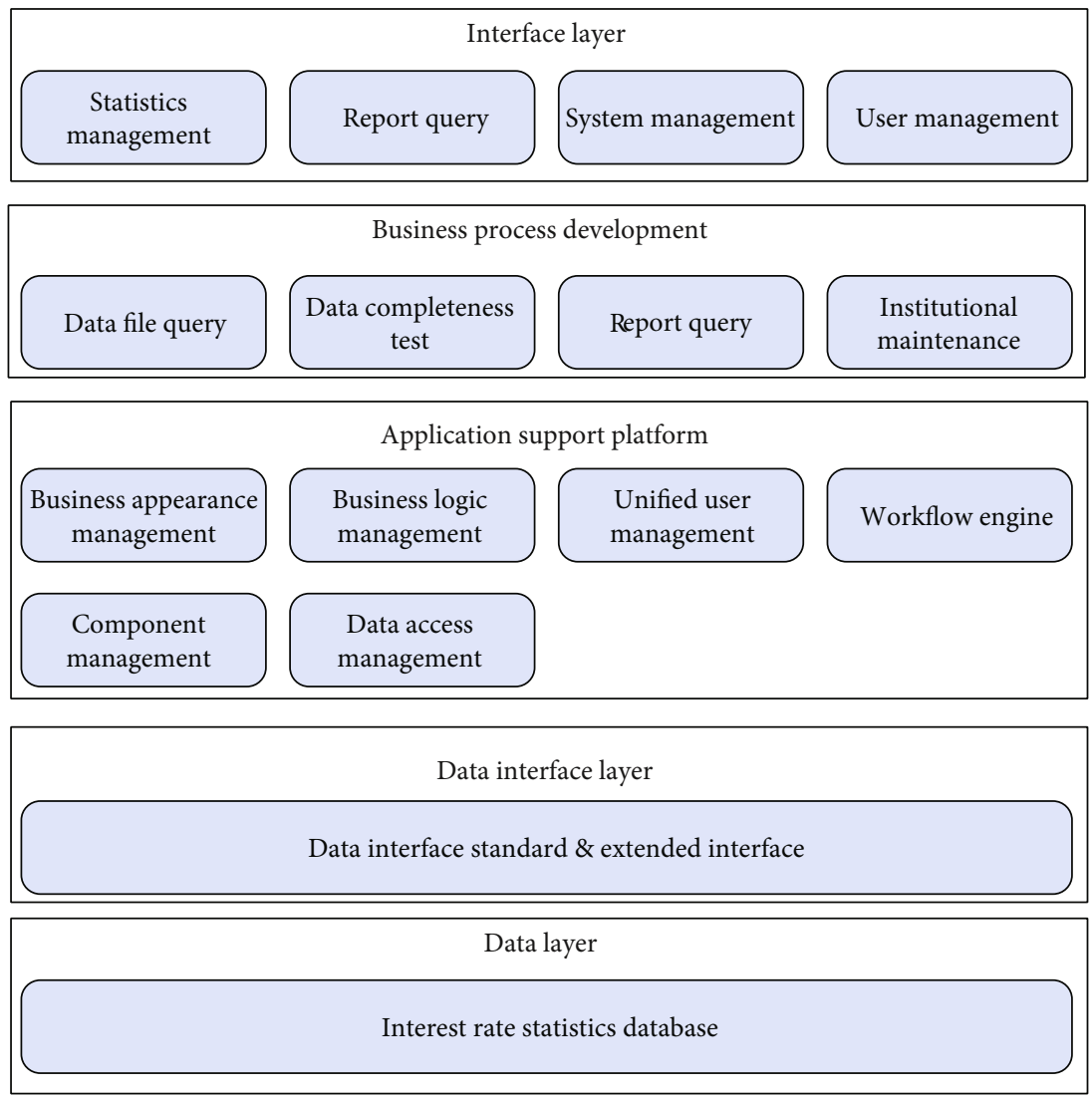

Figure 4: System structure of statistical system of bank interest rate. 


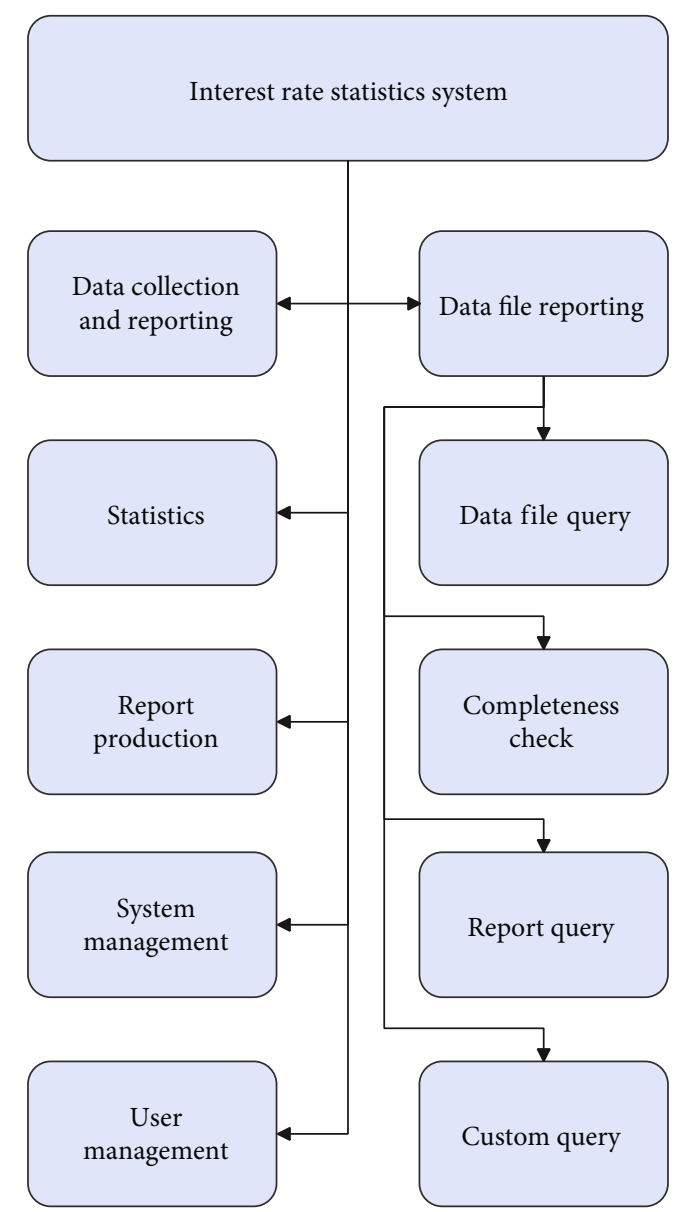

Figure 5: The modular structure of the statistical system of bank interest rates.

From the architecture diagram in the above figure, we can see that the client level is the interface between the user and the system, which is mainly implemented by JSP pages. In the corresponding layers, JSP, JavaBean, and Servlet have a clear division of labor. In the MVC framework, we use the more mature Struts framework and use the Action layer in the Struts framework to call the Javabeans in the business layer to complete various business functions. In the implementation technology of the database layer, JDBC technology is used to realize the access of other layers to the database, including database update and storage. What needs to be explained here is that Struts is just an implementation of MVC; after all, it is still an MVC development structure.

The modular design of the system comes from the needs of various financial institutions, mainly commercial banks and financial regulatory agencies, the demand specifications formed by the research, and the business needs and expected goals of each unit in the interest rate statistics work. The bank interest rate statistical analysis system is divided into five modules: data collection and reporting, data statistics, report generation, user management, system maintenance, and management. The module structure diagram is shown in Figure 5.

The data collection module is mainly composed of three modules: data upload, data verification, and data integrity check. Data upload includes data file reporting, data file query after the report is completed, data integrity check after the query is correct, and the integrity check passes after the data verification; the data reading status will be displayed after the data verification. You can check whether the data is read successfully or not. At the same time, you can query the number of data records after the data verification to prepare for missing or wrong reports. Afterwards, a data integrity report can be generated. The data integrity report is a prerequisite for data statistics and also a prerequisite for the data statistics module.

The functional structure diagram of the data collection and reporting module is shown in Figure 6.

After confirming that all the basic interest rate information tables are correctly entered into the database, the system performs summary calculations. In summary calculations, each statistical template is subjected to background summary calculation according to the specific calculation formula of each report. After the calculation is completed, the summary results are saved in the database. Due to the large amount of calculation data and the long waiting time for users to generate report calculations, it is not feasible to dynamically generate reports when querying. In order to solve this problem, the system adopts the following schemes for data aggregation: (1) the server performs centralized back-end summary in a certain period of time, generates intermediate results, and stores them in the 


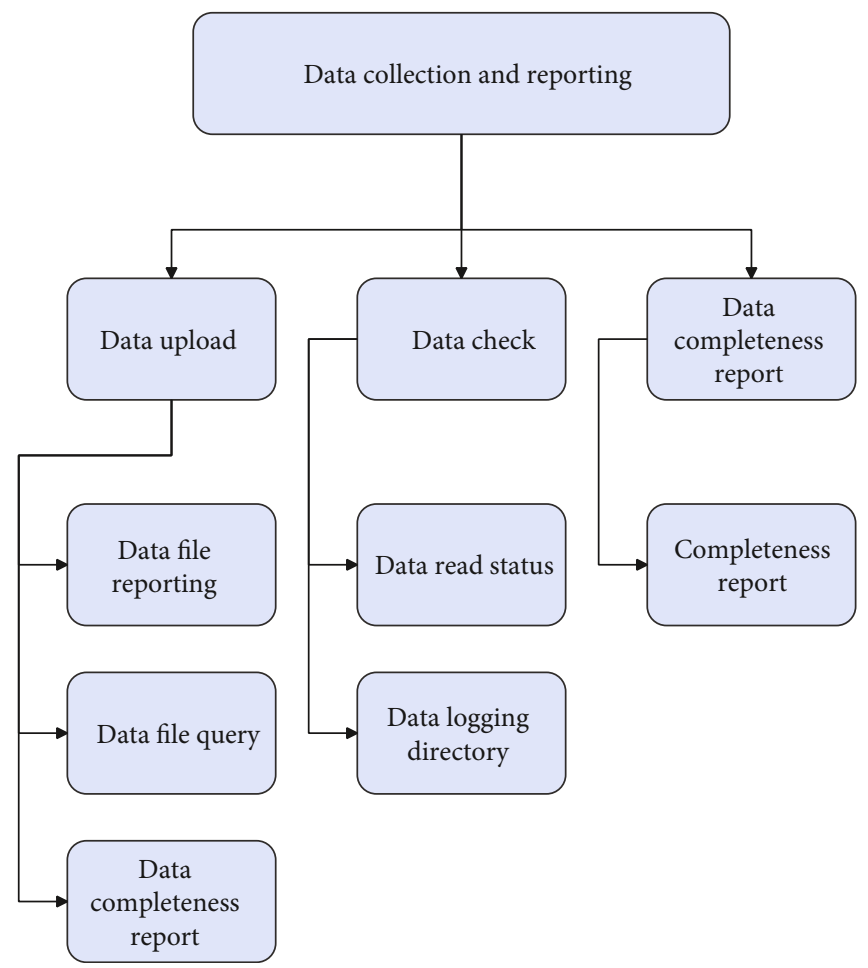

FIgURE 6: The structure diagram of the data collection and reporting module.

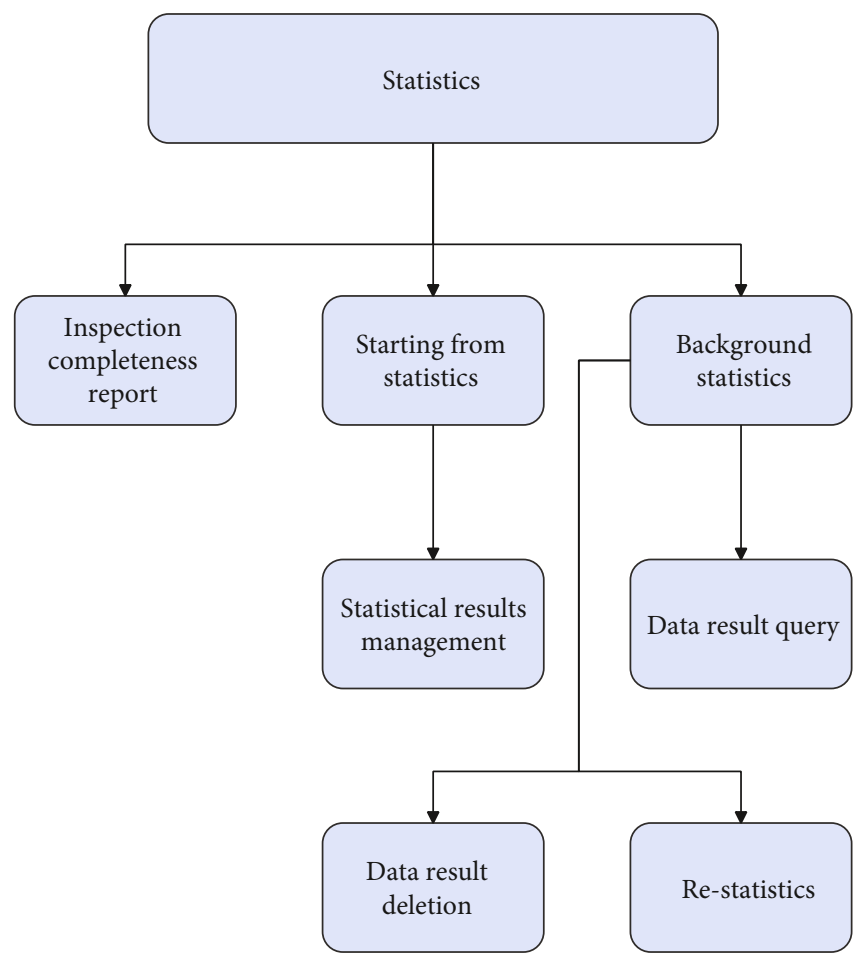

Figure 7: Structure diagram of data statistic module.

database. When users generate reports, they directly extract data from the intermediate results. (2) The function of summary calculation is triggered by the statisticians of the branches of the People's Bank of China to calculate all the data of the whole province, and the statisticians of each central branch will no longer perform the operation of summary calculation. (3) The administrator can trigger data aggregation when off-duty, and use off-duty time for 


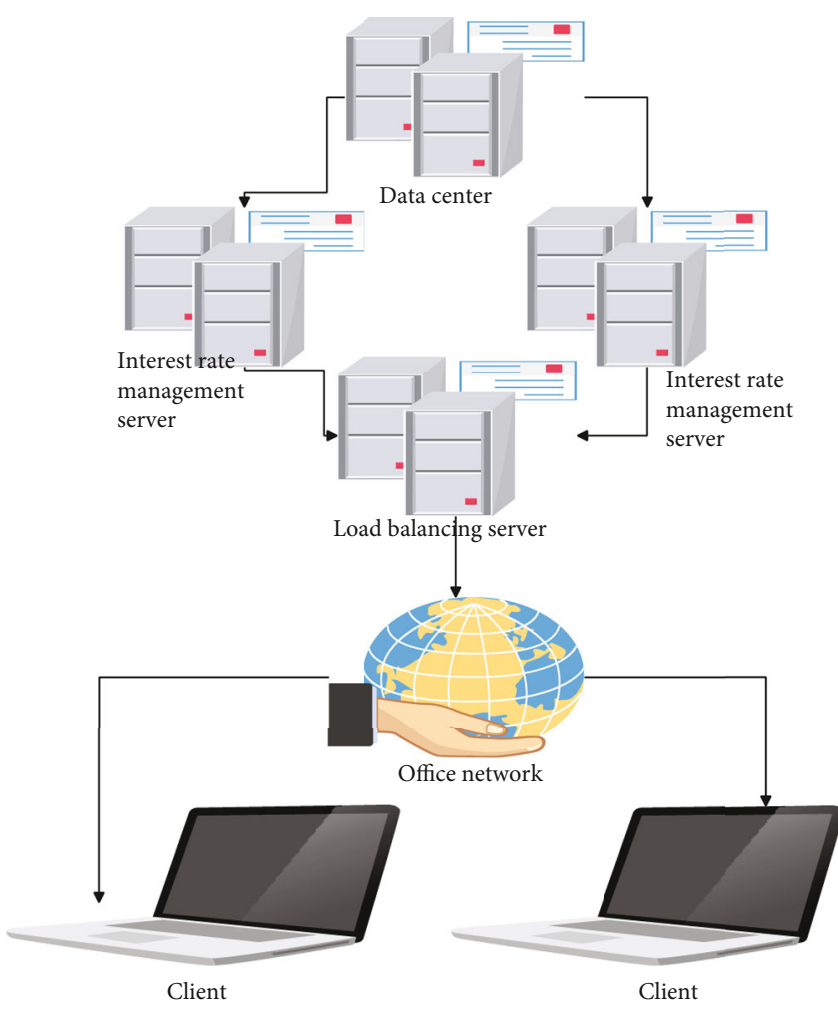

FIGURE 8: Schematic diagram of system physical deployment.

aggregation to reduce server pressure. The data summary statistics module is composed of three parts: completeness test report, data statistics trigger, and data statistics result management, as shown in Figure 7:

The interest rate management system is based on the B/S architecture and is developed and implemented using the JAVA programming language. The overall architecture is mainly composed of the browser side and the server side. The browser side is the entrance to access and use the system, and the server side is the business processing service provider and data processing and storage part of the entire system. The physical deployment diagram of the system is shown in Figure 8.

In order to ensure the stable and efficient operation of the system at the hardware level, the relevant parameters of current hardware manufacturers are fully studied. In terms of hardware selection, it is necessary to consider the needs of the system itself and also consider the development possibilities and trends of the bank's future deposits and loans.

\section{Performance Verification of Bank Interest Rate Analysis System}

After constructing the bank interest rate fluctuation model based on computer statistics and machine learning, in order to verify the effectiveness of the system in this paper, the system model is verified and analyzed. First of all, this article analyzes the stability of the system. The system constructed in this article requires a large amount of data processing. Therefore, it is necessary to ensure that the interest rate
TABLE 1: Statistical table of system stability.

\begin{tabular}{|c|c|c|c|c|c|}
\hline Number & $\begin{array}{c}\text { Data } \\
\text { running } \\
\text { speed } \\
(\mathrm{ms})\end{array}$ & Number & $\begin{array}{c}\text { Data } \\
\text { running } \\
\text { speed } \\
(\mathrm{ms})\end{array}$ & Number & $\begin{array}{c}\text { Data } \\
\text { running } \\
\text { speed } \\
(\mathrm{ms})\end{array}$ \\
\hline 1 & 115.1 & 29 & 131.3 & 57 & 148.0 \\
\hline 2 & 120.4 & 30 & 134.1 & 58 & 122.2 \\
\hline 3 & 129.5 & 31 & 114.2 & 59 & 120.3 \\
\hline 4 & 139.0 & 32 & 100.8 & 60 & 142.7 \\
\hline 5 & 143.4 & 33 & 130.2 & 61 & 136.9 \\
\hline 6 & 124.5 & 34 & 124.4 & 62 & 127.1 \\
\hline 7 & 132.1 & 35 & 126.3 & 63 & 123.4 \\
\hline 8 & 145.3 & 36 & 141.0 & 64 & 121.4 \\
\hline 9 & 113.6 & 37 & 141.7 & 65 & 100.4 \\
\hline 10 & 127.0 & 38 & 106.0 & 66 & 109.8 \\
\hline 11 & 113.6 & 39 & 142.2 & 67 & 145.7 \\
\hline 12 & 120.1 & 40 & 116.0 & 68 & 142.8 \\
\hline 13 & 100.6 & 41 & 115.1 & 69 & 107.6 \\
\hline 14 & 126.8 & 42 & 101.9 & 70 & 149.3 \\
\hline 15 & 140.5 & 43 & 121.2 & 71 & 113.0 \\
\hline 16 & 110.8 & 44 & 138.3 & 72 & 143.7 \\
\hline 17 & 100.2 & 45 & 140.1 & 73 & 125.0 \\
\hline 18 & 138.7 & 46 & 141.2 & 74 & 105.3 \\
\hline 19 & 124.0 & 47 & 131.3 & 75 & 132.9 \\
\hline 20 & 133.7 & 48 & 135.1 & 76 & 130.2 \\
\hline 21 & 100.6 & 49 & 107.3 & 77 & 147.6 \\
\hline 22 & 102.5 & 50 & 139.4 & 78 & 104.0 \\
\hline 23 & 131.8 & 51 & 102.0 & 79 & 134.1 \\
\hline 24 & 107.7 & 52 & 146.1 & 80 & 119.3 \\
\hline 25 & 139.6 & 53 & 129.9 & 81 & 119.2 \\
\hline 26 & 113.6 & 54 & 134.8 & 82 & 123.9 \\
\hline 27 & 128.9 & 55 & 130.4 & 83 & 128.7 \\
\hline 28 & 122.3 & 56 & 130.6 & 84 & 120.5 \\
\hline
\end{tabular}

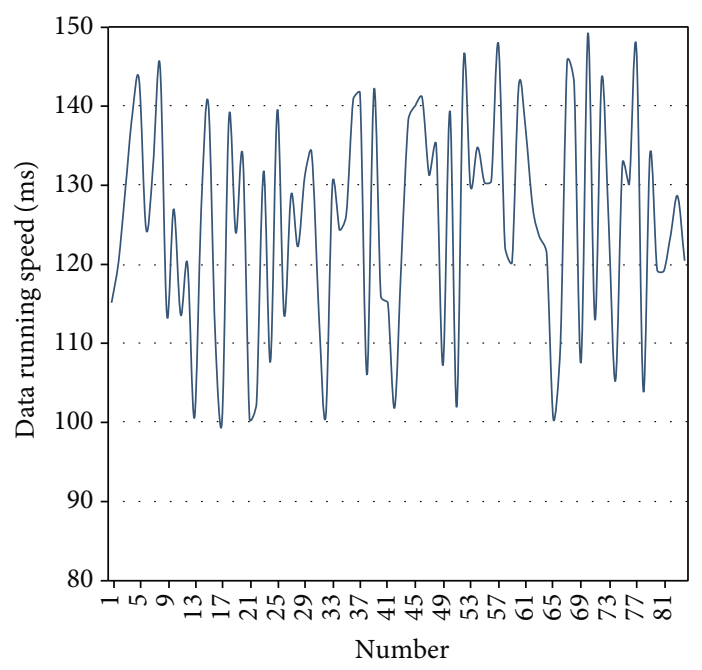

Figure 9: Statistical diagram of system stability. 
TABLE 2: Statistical table of the bank interest rate analysis effect.

\begin{tabular}{|c|c|c|c|c|c|}
\hline Number & $\begin{array}{l}\text { Interest } \\
\text { rate } \\
\text { analysis } \\
\text { effect }\end{array}$ & Number & $\begin{array}{l}\text { Interest } \\
\text { rate } \\
\text { analysis } \\
\text { effect }\end{array}$ & Number & $\begin{array}{c}\text { Interest } \\
\text { rate } \\
\text { analysis } \\
\text { effect }\end{array}$ \\
\hline 1 & 97.6 & 29 & 96.9 & 57 & 93.2 \\
\hline 2 & 93.5 & 30 & 97.5 & 58 & 80.5 \\
\hline 3 & 78.7 & 31 & 82.9 & 59 & 82.7 \\
\hline 4 & 92.2 & 32 & 79.8 & 60 & 80.3 \\
\hline 5 & 97.0 & 33 & 94.3 & 61 & 75.5 \\
\hline 6 & 91.5 & 34 & 78.9 & 62 & 83.5 \\
\hline 7 & 83.8 & 35 & 77.9 & 63 & 76.6 \\
\hline 8 & 82.1 & 36 & 79.5 & 64 & 75.6 \\
\hline 9 & 75.7 & 37 & 76.7 & 65 & 76.9 \\
\hline 10 & 75.6 & 38 & 85.4 & 66 & 80.2 \\
\hline 11 & 87.0 & 39 & 85.6 & 67 & 77.2 \\
\hline 12 & 78.2 & 40 & 85.1 & 68 & 95.4 \\
\hline 13 & 97.6 & 41 & 75.9 & 69 & 90.3 \\
\hline 14 & 88.2 & 42 & 79.9 & 70 & 96.8 \\
\hline 15 & 97.0 & 43 & 96.0 & 71 & 91.2 \\
\hline 16 & 85.1 & 44 & 78.0 & 72 & 87.6 \\
\hline 17 & 77.8 & 45 & 75.8 & 73 & 76.7 \\
\hline 18 & 80.8 & 46 & 79.1 & 74 & 86.1 \\
\hline 19 & 83.5 & 47 & 89.8 & 75 & 76.1 \\
\hline 20 & 93.5 & 48 & 81.0 & 76 & 89.7 \\
\hline 21 & 97.6 & 49 & 92.5 & 77 & 97.4 \\
\hline 22 & 90.0 & 50 & 88.8 & 78 & 89.0 \\
\hline 23 & 93.8 & 51 & 94.8 & 79 & 92.9 \\
\hline 24 & 88.4 & 52 & 77.3 & 80 & 89.6 \\
\hline 25 & 76.0 & 53 & 91.3 & 81 & 77.1 \\
\hline 26 & 84.4 & 54 & 78.5 & 82 & 94.4 \\
\hline 27 & 96.1 & 55 & 93.4 & 83 & 76.3 \\
\hline 28 & 78.0 & 56 & 79.9 & 84 & 78.8 \\
\hline
\end{tabular}

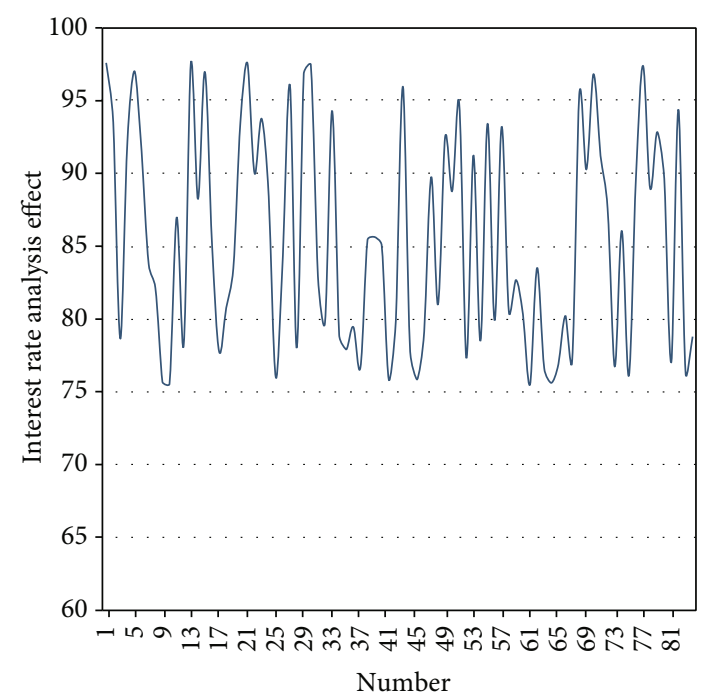

FIgURE 10: Statistical table of the bank interest rate analysis effect. analysis model itself has a certain degree of stability and has the ability to continue working after processing a large amount of data. Finally, this paper uses a large amount of random financial data to train and detects the running speed of the model in this paper. The results are shown in Table 1 and Figure 9.

From the above analysis results, we can see that the bank interest rate fluctuation analysis model constructed in this paper has always performed well in the data processing process. On this basis, the bank interest rate analysis effect is evaluated, and the results are shown in Table 2 and Figure 10.

It can be seen that the bank interest rate fluctuation model based on computer statistical model and machine learning constructed in this paper has good results.

\section{Conclusion}

With the steady progress of financial institution reform and interest rate marketization, in the context of the People's Bank of China continuing to expand the autonomy of interest rate pricing of financial institutions, it is necessary to summarize the loan interest rates of financial institutions, grasp the actual interest rate level, and continuously optimize interest rate policies. The development of the bank's interest rate statistical analysis system has realized the unification, standardization, and efficiency of the reporting and statistics of interest rate data of various financial institutions and has provided important data references for decisionmaking departments. The organization structure of this article is based on the needs of the various business requirements departments. Moreover, this article designs each functional module of the system in detail, designs each part of the system process and system examples, and determines the technical route of framework development using MVC + JDBC. In addition, this article combines requirements to construct a bank interest rate fluctuation analysis model based on statistical models and machine learning and analyzes and verifies through experiments. From the research results, it can be seen that the system constructed in this paper has a significant effect.

\section{Data Availability}

The labeled dataset used to support the findings of this study are available from the corresponding author upon request.

\section{Conflicts of Interest}

The author declares no competing interests.

\section{Acknowledgments}

This study is sponsored by the Key R\&D and Promotion Project (soft science research) in Henan Province (No. 212400410097) and Project of Philosophy and Social Science Planning of Henan Province (No. 2020JC31). 


\section{References}

[1] J. Fichtner, E. M. Heemskerk, and J. Garcia-Bernardo, "Hidden power of the big three?," Passive Index Funds, vol. 19, no. 2, pp. 298-326, 2017.

[2] C. Cueva, R. E. Roberts, T. Spencer et al., "Cortisol and testosterone increase financial risk taking and may destabilize markets," Scientific Reports, vol. 5, no. 1, pp. 1-16, 2015.

[3] C. J. Lee and E. B. Andrade, "Fear, excitement, and financial risk-taking," Cognition and Emotion, vol. 29, no. 1, pp. 178187, 2015.

[4] S. M. Bartram, G. W. Brown, and W. Waller, "How important is financial risk?," Journal of Financial and Quantitative Analysis, vol. 50, no. 4, pp. 801-824, 2015.

[5] W. W. Cooper, A. T. Kingyens, and J. C. Paradi, “Two-stage financial risk tolerance assessment using data envelopment analysis," European Journal of Operational Research, vol. 233, no. 1, pp. 273-280, 2014.

[6] W. Montford and R. E. Goldsmith, "How gender and financial self-efficacy influence investment risk taking," International Journal of Consumer Studies, vol. 40, no. 1, pp. 101-106, 2016.

[7] S. M. Wanjohi, J. G. Wanjohi, and J. M. Ndambiri, "The effect of financial risk management on the financial performance of commercial banks in Kenya," International Journal of Finance and Banking Research, vol. 3, no. 5, pp. 70-81, 2017.

[8] J. Magendans, J. M. Gutteling, and S. Zebel, "Psychological determinants of financial buffer saving: the influence of financial risk tolerance and regulatory focus," Journal of risk research, vol. 20, no. 8, pp. 1076-1093, 2017.

[9] E. S. Cole, D. Walker, A. Mora, and M. L. Diana, "Identifying hospitals that may be at most financial risk from Medicaid disproportionate-share hospital payment cuts," Health Affairs, vol. 33, no. 11, pp. 2025-2033, 2014.

[10] A. Zalik, "Resource sterilization: reserve replacement, financial risk, and environmental review in Canada's tar sands," Environment and Planning A, vol. 47, no. 12, pp. 2446-2464, 2015.

[11] C. Lucarelli, P. Uberti, and G. Brighetti, "Misclassifications in financial risk tolerance," Journal of Risk Research, vol. 18, no. 4, pp. 467-482, 2015.

[12] E. Y. Chan, "Physically-attractive males increase men's financial risk-taking," Evolution and Human Behavior, vol. 36, no. 5, pp. 407-413, 2015.

[13] T. West and A. C. Worthington, "Macroeconomic conditions and Australian financial risk attitudes, 2001-2010," Journal of Family and Economic Issues, vol. 35, no. 2, pp. 263-277, 2014.

[14] T. Tanimura, E. Jaramillo, D. Weil, M. Raviglione, and K. Lonnroth, "Financial burden for tuberculosis patients in low- and middle-income countries: a systematic review," European Respiratory Journal, vol. 43, no. 6, pp. 1763-1775, 2014.

[15] T. K. Scharding, "Imprudence and immorality: a Kantian approach to the ethics of financial risk," Business Ethics Quarterly, vol. 25, no. 2, pp. 243-265, 2015.

[16] J. Su and E. Furman, "A form of multivariate Pareto distribution with applications to financial risk measurement," ASTIN Bulletin, vol. 47, no. 1, pp. 331-357, 2017.

[17] G. W. Y. Wang, S. H. Woo, and J. Mileski, "The relative efficiency and financial risk assessment of shipping companies," Maritime Policy \& Management, vol. 41, no. 7, pp. 651-666, 2014.
[18] J. Linarelli, "Luck, justice and systemic financial risk," Journal of Applied Philosophy, vol. 34, no. 3, pp. 331-352, 2017.

[19] P. Allen and C. Petsoulas, "Pricing in the English NHS quasi market: a national study of the allocation of financial risk through contracts," Public Money \& Management, vol. 36, no. 5, pp. 341-348, 2016.

[20] J. Thomä and H. Chenet, "Transition risks and market failure: a theoretical discourse on why financial models and economic agents may misprice risk related to the transition to a lowcarbon economy," Journal of Sustainable Finance \& Investment, vol. 7, no. 1, pp. 82-98, 2017.

[21] O. Sosnovska and M. Zhytar, "Financial architecture as the base of the financial safety of the enterprise," Baltic Journal of Economic Studies, vol. 4, no. 4, pp. 334-340, 2018.

[22] D. Acemoglu, A. Ozdaglar, and A. Tahbaz-Salehi, "Systemic risk and stability in financial networks," American Economic Review, vol. 105, no. 2, pp. 564-608, 2015.

[23] R. Castellano, R. Cerqueti, and G. Rotundo, "Exploring the financial risk of a temperature index: a fractional integrated approach," Annals of Operations Research, vol. 284, no. 1, pp. 225-242, 2020.

[24] C. J. Kim, "Unobserved-component time series models with Markov-switching heteroscedasticity: Changes in regime and the link between inflation rates and inflation uncertainty," Annals of Operations Research, vol. 11, no. 3, pp. 341-349, 1993. 